Letter to the Editor

\title{
Relationship between reticular pseudodrusen and choroidal thickness in intermediate age-related macular degeneration: response
}

\author{
Chi YD Ho MBBS, ${ }^{1,2}$ Jia J Lek Boptom, ${ }^{1,2}$ Khin Z Aung MBBS, ${ }^{1,2}$ Myra B McGuinness \\ MBiostat, ${ }^{1,2}$ Chi D Luu PhD ${ }^{1,2}$ and Robyn H Guymer PhD FRANZCO ${ }^{1,2}$
}

1. Centre for Eye Research Australia, Royal Victorian Eye and Ear Hospital, and

2. Department of Surgery (Ophthalmology), The University

of Melbourne, Melbourne, Victoria, Australia

Correspondence: Dr Chi YD Ho, Macular Research, Centre for Eye Research

Australia, Level 8, 32 Gisborne Street, East Melbourne, Vic. 3002,

Australia. Email: cy.doreen.ho@gmail.com

Received 20 April 2018; accepted 23 April 2018

Conflict of interest: None

Funding sources: None

This is the author manuscript accepted for publication and has undergone full peer review but has not been through the copyediting, typesetting, pagination and proofreading process, which may lead to differences between this version and the Version of Record. Please cite this article as doi: 10.1111/ceo.13317

This article is protected by copyright. All rights reserved. 
We thank Invernizzi, Nguyen and Gillies ${ }^{1}$ for their interest in our paper "Relationship between reticular pseudodrusen and choroidal thickness in intermediate age-related macular degeneration". ${ }^{2}$

This was a large cross-sectional study of participants with intermediate age-related macular degeneration (iAMD) who were selected without reference to their reticular pseudodrusen (RPD) status. Similar to previous studies, we found that choroidal thickness (ChT) was, on average, thinner among participants with RPD compared to those without in an unadjusted univariate analysis. However, after adjusting for known and potential confounders (i.e. age, gender, smoking status and refractive error), we found no evidence of an association between the presence of RPD and $\mathrm{ChT}$. The only parameters that significantly associated with ChT in adjusted model were age and refractive error. As seen in Figure 4 of our original paper, age was strongly associated with ChT in eyes without RPD. The ChT of all eyes with RPD were well within the $95 \%$ prediction interval of non-RPD eyes, indicating that there was no significant deviation in ChT between eyes with and without RPD. To avoid bias, the data in Figure 4 should be interpreted with statistical rigor rather than from subjective visualisation of selected subset data.

Similarly, Cheng et al. reported that, after adjustment for age, mean ChT was not significantly thinner among eyes with RPD. ${ }^{3}$ However, they did find an association between RPD and ChT among participants who were less than 82 years old. As reported, we did not find the choroid to be significantly thinner among younger participants after stratifying by age, neither following stratification at 82 nor 70 years of age. We did go on further to stratify participants into quartile age groupings (not published), and did not find any significant difference in ChT between those with and without RPD in any age category. A possible explanation for the discrepancy between Cheng's and our findings is that refractive error was not adjusted for in 
Cheng's study but it was adjusted for in our study. It is possible that participants with RPD in Cheng's study had a greater refractive error than those without RPD, particularly those younger than 82 years.

Other groups ${ }^{4-6}$ have reported an association between RPD and choroidal thinning. However, given our large sample, homogenous phenotype of iAMD and proper adjustment for known and potential confounders, we believe that our results support our conclusion that the association between RPD and a thin choroid is largely due to both RPD and choroidal thickness being highly correlated with age. Unlike Invernizi et al. has postulated, we did not at any stage infer any causal relationship between $\mathrm{ChT}$ and the aetiology of RPD on the basis of our findings. Further longitudinal studies will be interesting to determine how both RPD and ChT change over time.

\section{REFERENCES}

1. Invernizzi A, Nguyen V, Gillies M. Relationship between reticular pseudodrusen and choroidal thickness in intermediate age-related macular degeneration: comment. Clin Experiment Ophthalmol 2018; 46: pp-pp

2. Ho C, Lek J, Aung K, McGuinness M, Luu C, Guymer R. Relationship between reticular pseudodrusen and choroidal thickness in intermediate age-related macular degeneration. Clin Experiment Ophthalmol. 2018; 46: pp-pp.

3. Cheng $H$, Kaszubski P, Hao H, Saade $C$, Cunningham $C$, Freund $K$, et al. The Relationship Between Reticular Macular Disease and Choroidal Thickness. Current eye research. 2016;41:1492-7. 
4. Querques G, Querques L, Forte R, Massamba N, Coscas F, Souied E. Choroidal changes associated with reticular pseudodrusen. IOVS. 2012;53(3):125863.

5. Thorell M, Goldhardt R, Nunes R, Filjo C, Abbey A, Kuriyan A. Association Between Subfoveal Choroidal Thickness, Reticular Pseudodrusen, and Geographic Atrophy in Age-Related Macular Degeneration. Ophthalmic Surgery, Lasers \& Imaging Retina. 2015;46(5).

6. Haas P, Esmaeelpour M, Ansari-Shahrezaei S, Drexler W, Binder S. Choroidal Thickness in Patients With Reticular Pseudodrusen Using 3D 1060-nm OCT Maps. IOVS. 2014;55(4):2674-81. 


\section{University Library}

\section{- M M I N E R VA \\ A gateway to Melbourne's research publications}

Minerva Access is the Institutional Repository of The University of Melbourne

Author/s:

Ho, CYD;Lek, JJ;Aung, KZ;McGuinness, MB;Luu, CD;Guymer, RH

Title:

Relationship between reticular pseudodrusen and choroidal thickness in intermediate agerelated macular degeneration: response

Date:

2018-11-01

Citation:

Ho, C. Y. D., Lek, J. J., Aung, K. Z., McGuinness, M. B., Luu, C. D. \& Guymer, R. H. (2018). Relationship between reticular pseudodrusen and choroidal thickness in intermediate age-related macular degeneration: response. CLINICAL AND EXPERIMENTAL OPHTHALMOLOGY, 46 (8), pp.967-968. https://doi.org/10.1111/ceo.13317.

Persistent Link:

http://hdl.handle.net/11343/283946 